\title{
A hybrid of bovine pancreatic ribonuclease and human angiogenin: an external loop as a module controlling substrate specificity?
}

\author{
Journal Article \\ Author(s): \\ Allemann, Rudolf K.; Presnell, Scott R.; Benner, Steven A. \\ Publication date: \\ 1991 \\ Permanent link: \\ https://doi.org/10.3929/ethz-b-000422991
}

Rights / license:

In Copyright - Non-Commercial Use Permitted

Originally published in:

Protein Engineering, Design \& Selection 4(7), https://doi.org/10.1093/protein/4.7.831 


\section{A hybrid of bovine pancreatic ribonuclease and human angiogenin: an external loop as a module controlling substrate specificity?}

\author{
Rudolf K.Allemann ${ }^{1}$, Scott R.Presnell ${ }^{2}$ and \\ Steven A.Benner ${ }^{3}$ \\ Laboratory for Organic Chemistry, Swiss Federal Institute of Technology. \\ $\mathrm{CH}-8092$ Zurich, Switzerland \\ 'Present address: Laboratory of Eukaryotic Molecular Genetics, MRC \\ Natıonal Institute for Medical Research, Mill Hill, London NW7 IAA, UK \\ ${ }^{2}$ Present address. Computer Graphics Laboratory, Department of \\ Pharmaceutical Chemıstry, University of Calıfornia, San Francisco, USA \\ ${ }^{3}$ To whom correspondence should be addressed
}

A comparison of the sequences of three homologous ribonucleases (RNase $A$, angiogenin and bovine seminal RNase) identifies three surface loops that are highly variable between the three proteins. Two hypotheses were contrasted: (i) that this variation might be responsible for the different catalytic activities of the three proteins; and (ii) that this variation is simply an example of surface loops undergoing rapid neutral divergence in sequence. Three hybrids of angiogenin and bovine pancreatic ribonuclease (RNase) $A$ were prepared where regions in these loops taken from angiogenin were inserted into RNase $A$. Two of the three hybrids had unremarkable catalytic properties. However, the RNase A mutant containing residues 63-74 of angiogenin had greatly diminished catalytic activity against uridylyl-( $\left(3^{\prime}-5^{\prime}\right)$ adenosine (UpA), and slightly increased catalytic activity as an inhibitor of translation in vitro. Both catalytic behaviors are characteristic of angiogenin. This is one of the first examples of an engineered external loop in a protein. Further, these results are complementary to those recently obtained from the complementary experiment, where residues 59-70 of RNase were inserted into angiogenin [Harper and Vallee (1989) Biochemistry, 28, 1875-1884]. Thus, the external loop in residues 63-74 of RNase $A$ appears to behave, at least in part, as an interchangeable 'module' that influences substrate specificity in an enzyme in a way that is isolated from the influences of other regions in the protein.

Key words: angiogenin/evolutionary guidance/folding pathway/ ribonuclease/site-directed mutagenesis

\section{Introduction}

Bovine pancreatic ribonuclease $A$ (RNase A) is a monomeric enzyme that hydrolyzes single-stranded RNA and dinucleotides such as uridylyl-( $\left.3^{\prime} \rightarrow 5^{\prime}\right)$-adenosine (UpA) (Blackburn and Moore, 1982). RNase A appears to play a special role in ruminant digestion (Barnard, 1969), a role that emerged only recently in evolutionary history (Stackhouse et al., 1990). It has little activity as either an inhibitor or a promoter of cell growth.

Angiogenin is a homolog of RNase A first isolated as an angiogenesis factor from tumor-cell-conditioned medium because of its ability to induce the growth of blood vessels in biological assay systems (Fett et al., 1985). Although a physiological role for angiogenin in the growth of tumors is far from certain, angiogenin itself is clearly necessary for this process (Folkman,
1972). The sequences of angiogenin and bovine RNase $A$ are $\sim 65 \%$ different (Kurachi et al., 1985; Strydom et al., 1985). Angiogenin also differs from RNase $A$ in that it shows little enzymatic activity as a ribonuclease against small substrates; in particular, angiogenin hydrolyzes UpA only $\sim 2 \%$ as fast as RNase A (Shapiro et al., 1986). Angiogenin has, however, a characteristic ribonuclease activity against larger RNA molecules. In particular, angiogenin is a somewhat better inhibitor of protein synthesis in the rabbit reticulocyte lysate system than pancreatic RNase A, where its principal target appears to be ribosomal RNA (St Clair et al., 1987).

Seminal RNase (D'Alessio and Leone, 1963), a third homologous protein ( $81 \%$ sequence identical with RNase A; Suzuki et al., 1987), has still different catalytic and biological activities (Taniguchi and Libonati, 1974). Unlike the digestive enzyme, seminal RNase is a covalent dimer (Capasso et al., 1983; Mazzarell et al., 1987), catalyzes preferentially the hydrolysis of double-stranded RNA and DNA-RNA hybrids (Taniguchi and Libonati, 1974), and has potent anti-tumor activity both in vitro and in vivo (Matousek, 1973; Vescia et al., 1980; Vescia and Tramontano, 1981).

The homology between potential tumor growth promoters, tumor growth inhibitors and digestive RNases is especially interesting in the context of the hypothesis that extracellular RNA molecules serve as intercellular communicator molecules important in mammalian development (Wissler et al., 1986; Benner, 1987, 1988; Benner and Allemann, 1989). Therefore, we examined the sequences of these proteins in an effort to correlate specific sequence differences with the differences in their catalytic and biological activities (Nambiar et al., 1986).

Seminal RNase and RNase A differ greatly in three regions (Figure 1), between residues 16-20, residues $62-66$ and residues $111-115$, in addition to a region (residues $28-38$ ) that appears from crystallographic studies to be responsible for the dimeric structure of seminal RNase (Capasso et al., 1983; Mazzarella et al., 1987). The sequences of RNase A and angiogenin differ throughout the alignment, as expected given their greater sequence divergence. However, three regions displaying variability between angiogenin and RNase A, residues $15-24$, residues $63-74$ and residues $112-115$ (where the numbers refer to positions in the sequence for RNase A), overlap the highly variable regions between seminal RNase and RNase A. In all three segments, residues in the digestive RNase are deleted in angiogenin, and the deletion is accompanied by many point mutations in the immediate environment. In the region from residues 63 to 74 , a disulfide bond is deleted (Beintema et al., 1985).

The fact that both angiogenin and seminal RNase differ significantly from RNase $A$ in the same three regions could have many explanations, including trivial ones. For example, the three regions of highest variation, identified by the process mentioned above, are all surface loops in RNase A (Figure 2), and surface loops are known to undergo rapid sequence divergence often regarded as neutral drift (Kimura, 1982). This would normally 


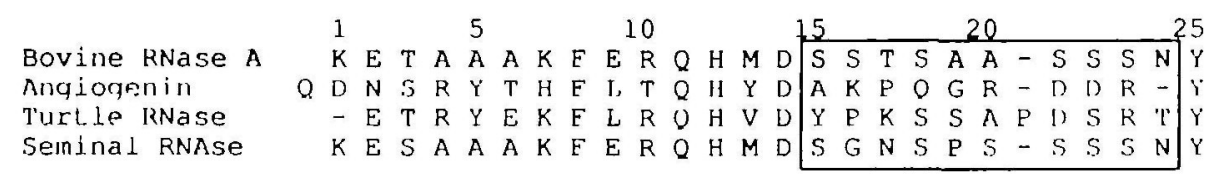

Bovine RNase A
Angiogenin
Turt le RNase
Seminal RNAse

$$
30 \quad 35 \quad 40 \quad 55 \quad 50
$$

C N Q M M K S R N L T K D R C K P V N T F V H E S L A C E S I M R R R G L T S P - C K D I N T F I H G N K R $C N Q M M Q R R G M T S P V C K F T N T E V H A S A \wedge$ Seminal RNAse

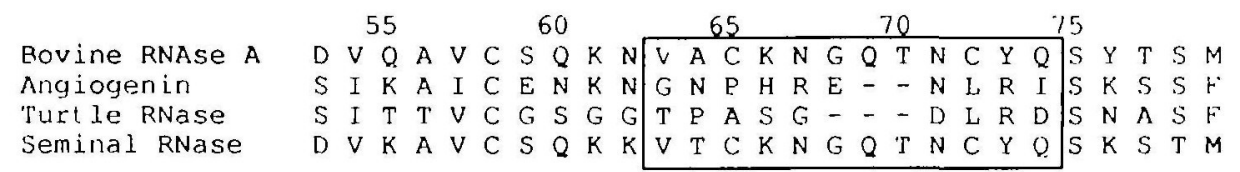

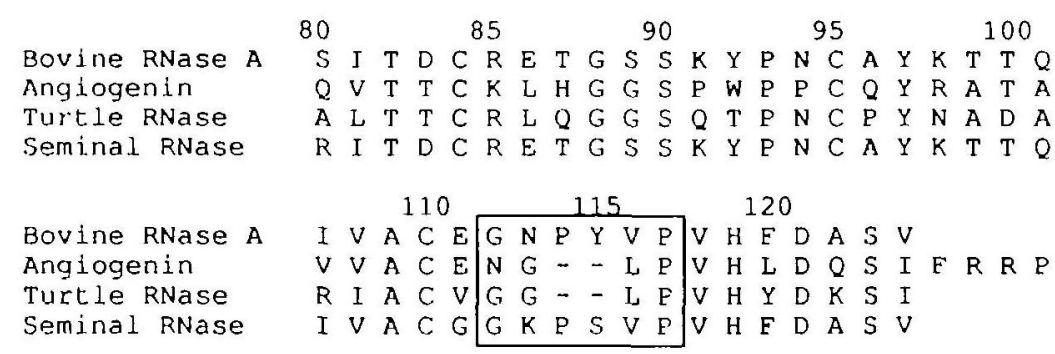

Fig. 1. Sequence alignment of bovine pancreatic RNase A, human angiogenin, turtle RNase and bovine seminal RNase. Regions of high variability between angiogenin and RNase $A$ (residues $15-24,49-53,63-74$ and 112-116) are boxed.

imply that the structural differences noted in Figure 1 have no significance regarding the biological and catalytic differences observed in the three proteins (Presnell, 1988).

However, the assumption that variation in surface loops is neutral is almost certainly not universally valid (Hill and Hastie, 1987; Laskowski et al., 1987), and it is conceivable that structural variation in these regions may be determined by the different chemical and biological activities of these RNase homologs. Further, the three-way sequence comparison greatly limits the number of experiments that might be attempted based on a comparison of the sequences of angiogenin and RNase alone. Therefore, we have prepared hybrids of RNase $A$ and angiogenin in these three regions.

\section{Materials and methods \\ Materials}

Restriction endonucleases, T4 polynucleotide kinase and T4 DNA ligase were from New England Biolabs; other enzymes were from Boehringer-Mannheim. Standard procedures were used to prepare genetic constructions (Seed, 1983), and are described in detail elsewhere (Allemann, 1989). UpA was from Sigma. Oligonucleotides were synthesized on an Applied Biosystems model $380 \mathrm{~A}$ synthesizer using phosphoramidite chemistry and purified either by PAGE on $16 \%$ gels or, in the case of short oligonucleotides, by TLC (McGeehan and Benner, 1989). DNA sequencing was carried out using a Sequenase DNA sequencing kit. The kit for in vitro translation and brome mosaic virus BMV RNA were from Promega Biotech.

Construction of the genes for the hybrid proteins

Hybrid proteins containing a short segment of angiogenin introduced into RNase A (Figure 1) were designated RA(15-24), $\mathrm{RA}(63-74)$ and $\mathrm{RA}(112-116)$. Genes for these mutants were constructed from a synthetic gene for RNase A (Nambiar et al., 1984, 1987) by modular mutagenesis procedures, taking

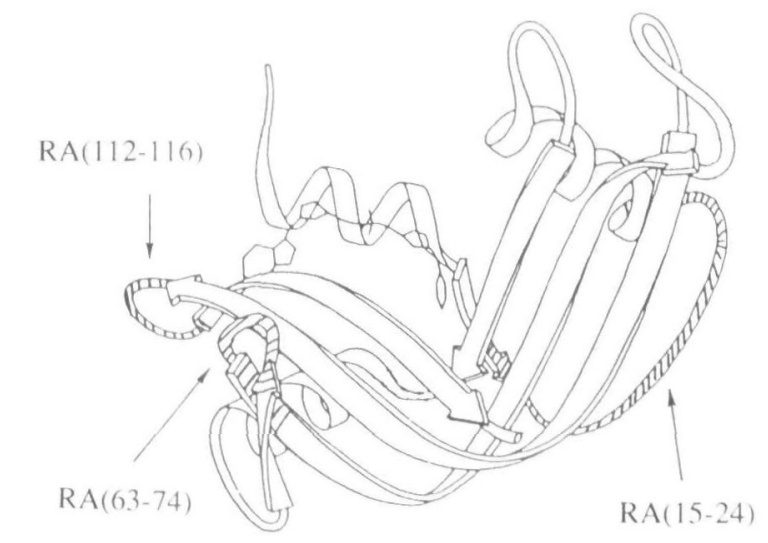

Fig. 2. Ribbon diagram of the crystal structure of bovine pancreatic RNase $A$ indicating the three regions of high sequence divergence of human angiogenın (the numbers refer to positions in the sequence of RNase A).

advantage of the unique restriction sites placed throughout the gene. Details of the constructions are reported elsewhere (Presnell, 1988; Allemann, 1989). All constructions were verified by total sequence analysis.

\section{Expression of the hybrid proteins}

Constructed genes for the mutants were expressed in Escherichia coli under the control of the lambda $\mathrm{p}_{\mathrm{L}}$ promoter, using the expression vector described previously (McGeehan and Benner, 1989). This system yields free RNase bearing an N-terminal methionine residue, as determined by Edman degradation. Control experiments with RNase mutants with and without this methionine (Stackhouse et al., 1990) have failed to detect evidence for an impact of this additional methionine on the behavior of several mutant proteins. Competent E.coli cells (N4830/cI857ts, containing the gene for a temperature-sensitive lambda cI repressor) were transformed with the expression vector 
by the method of Hanahan (1983); positive transformants were isolated and the genes sequenced. Transcription was induced by heat shock at $42^{\circ} \mathrm{C}$ following the method of McGeehan and Benner (1989), and optimal times for harvest (25-30 $\mathrm{min}$ ) were determined individually for each hybrid by following the course of induction by Western blotting under denaturing conditions using polyclonal antibody raised against denatured RNase A (Burnette, 1981).

\section{Reconstitution and purification of hybrid proteins}

The hybrid proteins were reconstituted and purified using a standard protocol (McGeehan and Benner, 1989). Following induction, cells from a 11 incubation mixture (OD at $550 \mathrm{~nm}$ 1.2) were suspended in 'denaturing buffer' [8 M urea, $40 \mathrm{mM}$ sarcosine, $20 \mathrm{mM}$ Tris $-\mathrm{HCl}, 20 \mathrm{mM} \mathrm{NaCl}, 20 \mathrm{mM}$ $\beta$-mercaptoethanol, $1 \mathrm{mM}$ ethylenediaminetetracetic acid (EDTA), pH 7.8] at $4^{\circ} \mathrm{C}$ and lysed in a French press (14 000 p.s.i.). The lysate was centrifuged, and the supernatant dialyzed (Amicon, cutoff 3500) against 'refolding buffer' [50 mM Tris $-\mathrm{HCl}, 100 \mathrm{mM} \mathrm{NaCl}, 1 \mathrm{mM}$ EDTA, $0.2 \mathrm{mM}$ phenylmethylsulfonyl fluoride (PMSF), $4 \mathrm{mM}$ oxidized glutathione, $4 \mathrm{mM}$ reduced glutathione, $0.02 \% \mathrm{NaN}_{3}, \mathrm{pH} 7.6$ ] over a period of $72 \mathrm{~h}$ (two changes, $2 \mathrm{l}$ each). The dialysate was then loaded onto a sizing column (Sephadex G-509, $120 \times 4.5 \mathrm{~cm}$ ) and the column was eluted (flow rate $5.1 \mathrm{ml} / \mathrm{h} / \mathrm{cm}^{2}$ ) with elution buffer (50 mM Tris $-\mathrm{HCl}, 100 \mathrm{mM} \mathrm{Nacl}, 1 \mathrm{mM}$ EDTA, $0.2 \mathrm{mM}$ PMSF, $0.02 \% \mathrm{NaN}_{3}, \mathrm{pH} 7.5$ ). This procedure removed $\sim 80 \%$ of the contaminating protein. The effluent containing the ribonuclease was dialyzed against affinity chromatography buffer ( $100 \mathrm{mM}$ ammonium acetate, $0.02 \% \mathrm{NaN}_{3}, \mathrm{pH} 6.2$ ) and further purified by affinity chromatography on pUp-agarose (Sigma, $5 \mathrm{ml}$ in a $1 \mathrm{~cm}$ diameter column), using $2^{\prime}, 3^{\prime}$-CMP in the affinity chromatography buffer as eluant. The proteins thus purified were pure by SDS-PAGE using both silver and Coomassie blue staining, as well as by immunoblotting.

\section{Kinetic analysis of hybrid proteins}

Steady-state kinetics were measured using UpA as substrate. The rate of hydrolysis of UpA $(100$ and $500 \mu \mathrm{M})$ at $25^{\circ} \mathrm{C}$ was measured in sodium acetate buffer $(\mathrm{pH} 5.0,100 \mathrm{mM})$ by coupling the reaction to the deamination of adenosine catalyzed by adenosine deaminase, which was followed at $265 \mathrm{~nm}$ using a molar extinction coefficient of $23600 \mathrm{M} / \mathrm{cm}$, according to the procedure of Ipata and Felicioli (1968). The concentration of RNase A was determined both by measuring its absorbance at $280 \mathrm{~nm}$ (absorbance of a $1 \%$ solution is 7.3 ; alternatively, at $278 \mathrm{~nm}$ the molar extinction coefficient is 9800 ) and by the Bio-Rad modification of the Bradford assay (Bradford, 1976). Concentrations of hybrid enzymes were determined by SDSPAGE using known amounts of RNase $A$ as standards.

\section{Inhibition of the rabbit reticulocyte systems}

The ability of various ribonucleases to inhibit the synthesis of proteins in rabbit reticulocyte lysate preparations was determined using a kit from Promega Biotech and BMV mRNA, following the procedure of the manufacturer and St Clair et al. (1987). The lysate was stored at $-80^{\circ} \mathrm{C}$ in aliquots $(200 \mu \mathrm{l})$ and used immediately after thawing. Lysate $(17.5 \mu \mathrm{l})$ in an Eppendorf tube was incubated with a defined amount of RNase $A$ or hybrids in the buffer (ammonium acetate, $100 \mathrm{mM}, \mathrm{pH} 6.2$ ) in a total volume of $22 \mu \mathrm{l}$ at $30^{\circ} \mathrm{C}$ for $15 \mathrm{~min}$. The mixture was then placed on ice, and human placental ribonuclease inhibitor (PRI; Amersham, 25 units in $1 \mu \mathrm{l}$ water) added. Independent experiments showed that the RNase hybrids were inhibited by PRI. The contents were mixed, centrifuged, retumed to ice, and then diluted with a solution $(1 \mu \mathrm{l})$ containing $\left[{ }^{35} \mathrm{~S}\right]$ methionine $(1440 \mathrm{Ci} / \mathrm{mmol}$, $15 \mathrm{mCi} / \mathrm{ml}, 0.5 \mu \mathrm{l}$ ) and 19 unlabeled amino acids (Promega, $1 \mathrm{mM}$ each, $0.5 \mu \mathrm{l}$ ). The mixture was again centrifuged, and translation initiated by adding mRNA $(1 \mu \mathrm{l}, 0.5 \mu \mathrm{g})$. Translation was allowed to proceed for $60 \mathrm{~min}$ at $30^{\circ} \mathrm{C}$. Two controls, one lacking message, the other lacking RNase, were run in parallel.

Following incubation, an aliquot $(1 \mu \mathrm{l})$ of the translation mixture was added to a solution $(1 \mathrm{ml})$ of sodium hydroxide $(1 \mathrm{~N})$ and hydrogen peroxide $(1.5 \%)$, the mixture incubated $\left(37^{\circ} \mathrm{C}\right.$, $10 \mathrm{~min})$, diluted with an ice-cold solution of trichloroacetic acid (TCA, $4 \mathrm{ml}, 25 \% \mathrm{w} / \mathrm{v}$ ), and $2 \%$ (w/v) casamino acids were added. The solution was mixed and placed on ice for $30 \mathrm{~min}$. The precipitated proteins were collected by filtration (Whatman $\mathrm{GF} / \mathrm{C}$ filter, $2.4 \mathrm{~cm}$ diameter) and the filter was washed with an ice-cold solution of TCA (10 ml, $8 \%)$, and then with acetone $(3 \mathrm{ml})$. The filter was dried by suction, transferred to a scintillation vial, and counted. Alternatively, aliquots of the translation mixture (samples and control in parallel) were run directly on a denaturing polyacrylamide gel, the gels dried, and directly scanned. All results are reported relative to RNase A.

\section{Results and discussion}

The preparation and expression of genes coding for the hybrids was uneventful. However, it is worth mentioning that in the refolding buffer used here, $\mathrm{RA}(63-74)$ recovers its catalytic activity slowly when compared with the rate with which native RNase A or the other hybrids recovered theirs. This is especially noteworthy as this hybrid lacks one of the four disulfide bonds found in RNase A. As the formation lof disulfide bonds might play an important role in the folding process (Creighton, 1979), the slow folding of $\operatorname{RA}(63-74)$ is, worth examining in further detail.

The catalytic activities with UpA as a substrate of the three hybrids, each having a short module of angiogenin introduced into a background of RNase $A$, show an interesting pattern (Table I). Two of the hybrid proteins, RA(15-24) and RA(112-116) have specific activities 55 and $22 \%$ that of RNase A with UpA as substrate. This diminished activity (by a factor of 2-5) is within the range normally observed for structurally altered proteins. More notable is the fact that the specific activity of the third hybrid, $\mathrm{RA}(63-74)$, is reduced by a factor of $60,<2 \%$ of the specific activity of RNase $A$.

This result would be uninteresting if the hybrid had generally diminished catalytic activity (due to unfolding, for example).

Table I. Specific activities of RNase A and RNase-angıogenin hybrids with UpA as substrate

\begin{tabular}{|c|c|c|c|c|}
\hline \multirow[t]{2}{*}{ Enzyme } & \multicolumn{2}{|l|}{$100 \mu \mathrm{M} U \mathrm{pA}$} & \multicolumn{2}{|l|}{$500 \mu \mathrm{M}$ UpA } \\
\hline & $\begin{array}{l}\text { Sp. act. } \\
(\mu \mathrm{mol} / \mathrm{mg} / \mathrm{mm})\end{array}$ & $\begin{array}{l}\text { Relative } \\
\text { sp. act. }\end{array}$ & $\begin{array}{l}\text { Sp açt." } \\
(\mu \mathrm{n} \text { ○l/mg/mın) }\end{array}$ & $\begin{array}{l}\text { Relative } \\
\text { sp. act. }\end{array}$ \\
\hline RNase A & $284 \quad(14.2)$ & 1 & $881.2(44.1)$ & 1 \\
\hline $\operatorname{RA}(15-24)$ & $162.9(8.1)$ & 057 & $462.7(231)$ & 053 \\
\hline $\operatorname{RA}(112-116)$ & $62.1(31)$ & 0.22 & $170.9(8.5)$ & 0.19 \\
\hline $\operatorname{RA}(63-74)$ & $44(02)$ & 0016 & $146(0.7)$ & 0017 \\
\hline
\end{tabular}

${ }^{\mathrm{a}}$ In sodium acetate buffer $(100 \mathrm{mM}, \mathrm{pH} 5.0)$ at $25^{\circ} \mathrm{C}$ : estimated standard error is given in parentheses. The reaction was followed spectrophotometrically at $265 \mathrm{~nm}$ in a coupled assay with adenosine deamınase. The concentration of RNase A was determıned spectrophotometrically at $280 \mathrm{~nm}$ using an extunction coefficient of $9800 \mathrm{M} / \mathrm{cm}$. Concentrations of hybrids were determined by scanning denaturing polyacrylamide gels (15\%) using dilutions of RNase $A$ as standards 
Therefore, the ability of the hybrids to inhibit in vitro translation (an increase in this activity is a characteristic of angiogenin; St Clair et al., 1987) was measured using the rabbit reticulocyte lysate system. The activities of two of the hybrid proteins, $\mathrm{RA}(15-24)$ and RA(112-116), were comparable or diminished when compared with RNase A (Figure 3 and Table II). However, the third hybrid RA(63-74), despite its greatly reduced catalytic activity against small ribonucleotide substrates, was somewhat better as an inhibitor of protein translation than RNase A (Table II). While the difference in activity between angiogenin and RNase A in this assay is small, the increase in the hybrid's activity as an inhibitor of translation over that of RNase $\mathrm{A}$ is about half that of angiogenin itself.

Since these experiments were completed, Harper and Vallee (1989) reported the results of experiments where a segment of angiogenin between positions 58 and 70 is replaced by the homologous segment of bovine pancreatic RNase A (residues $59-73$ ). This experiment is nearly the reciprocal of one of the experiments reported here. Remarkably, the results obtained are also largely reciprocal, in that the catalytic activity against small substrates (e.g. UpA) of the angiogenin containing a short loop of RNase A was - 200-fold greater than that of angiogenin itself. A short segment of RNase A, when inserted into angiogenin, appears to confer RNase-A-like catalytic properties on angiogenin, at least with respect to catalytic activity against UpA, and this segment corresponds to the segment of angiogenin reported here that confers angiogenin-like catalytic activity on RNase A when inserted into RNase A.

Thus, the region in RNase $A$ between positions 63 and 74 appears to behave, at least with respect to these details of catalytic activity, as an example of an interchangeable 'module' that influences substrate specificity in an enzyme in a way that is isolated, at least to some degree, from other regions in the protein. Such modules, of great interest to the protein engineer, have not been easy to find, as the analysis of the behavior of most mutants has proved to be complex. Further, this module would not have been easily identified by a simple comparison of the crystal structures of various RNases (Figure 2).

Crystallographic data suggest two sets of interactions between this loop (63-74) and the substrate. First, the $\epsilon$-amino group of Lys66 may form a salt bridge with the phosphate group of the substrate on the 5'-hydroxyl group of the ribose bearing the reactive phosphate in oligonucleotide substrates (MacPherson et al., 1986). This Lys is not present in the hybrid; the only basic residues present in the new loop near the appropriate region are a His and an Arg.

One might attempt to interpret the kinetic results reported here in terms of a loss of this salt bridge. Naively, however, one might expect this loss to alter most significantly the rate of hydrolysis of substrates that bear a phosphate group at this position. UpA does not have this phosphate; thus, the influence of the structural alterations described here on catalytic activity are the opposite of what one might expect based on this rationale.

Alternatively the structure of the complex of RNase $A$ and a phosphonate analog of UpA shows the $\epsilon$-oxygen group of Gln69 and the $\delta$-oxygen group of Asn 17 forming a binding site for the adenine ring in the UpA substrate through hydrogen bonding with the N(6) nitrogen (Richards and Wyckoff, 1973; Wodak et al., 1977). This interaction has been proposed to be important in the ability of RNase A to distinguish between adenine and guanine at this position in the substrate. Gln69 is, of course, missing in RA(63-74), and the Asn corresponding to Asn71 is almost certainly reoriented, given the shortness of the loop.

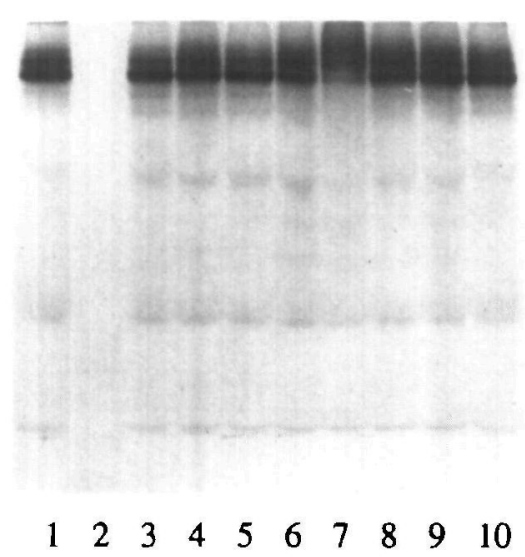

Fig. 3. Autoradiography of a $10 \%$ polyacrylamide gel of the in vitro translation products showing the effects of bovine pancreatic RNase A and $\mathrm{RA}(63-74)$ on the translational capacity of the RNA-dependent rabbit reticulocyte lysate system. The rabbit reticulocyte lysate was incubated with the indicated amounts of RNase A and $\operatorname{RA}(63-74)$ for $15 \mathrm{~mm}$ at $30^{\circ} \mathrm{C}$. The ribonucleolytic action of the digestive enzymes was quenched by the addition of PRI, control experiments showed that PRI was a potent inhibitor of RA(63-74). Translation was then initiated by the addition of BMV RNA. Lane 1, no ribonucleolytic enzymes added to preincubation mixture; lane 2, translation without added MBV RNA, lanes 3-6, preincubation in the presence of $20,30,40$ and $50 \mathrm{nM}$ RNase A; lanes 7-10, preincubation with $50,40,30$ and $20 \mathrm{nM} \operatorname{RA}(63-74)$.

Table II. Inhibition of translation by RNase $A$ and RNase-angiogenin hybrids

(A) Effect of varying concentrations of RNase A on translational capacity (determined by measuring the TCA-precipitable radioactivity in translation products-see Materials and methods) of rabbit reticulocyte lysate

\begin{tabular}{lcc}
\hline [RNase A] (nM) & \% Translation & o Inhibition \\
\hline 0 & 100 & 0 \\
40 & 57 & 43 \\
50 & 45 & 55 \\
60 & 30 & 70 \\
78 & 0 & 100 \\
\hline
\end{tabular}

(B) Protein concentrations (nM) of RNase A, RA(15-24), RA(112-116), $\mathrm{RA}(63-74)$ and angiogenin giving rise to a $50 \%$ inhibition of the translational capacity of rabbit reticulocyte lysate

\begin{tabular}{lll}
\hline Protein & $\begin{array}{l}\text { Protein concentration (nM) } \\
\text { giving } 50 \% \text { inhibition }^{\mathrm{a}}\end{array}$ & $\begin{array}{l}\text { \% Inhibition } \\
\text { relative to RNase A }\end{array}$ \\
\hline RNase A & $39(2.0)$ & 100 \\
RA(15-24) & $37(1.9)$ & 104 \\
RA(112-116) & $48(2.4)$ & 80 \\
RA(63-74) & $35(18)$ & 111 \\
Angiogenin $^{\mathrm{b}}$ & 32 & 122 \\
\hline
\end{tabular}

${ }^{a}$ Value determined by measurement of translation products in a set of experiments at several concentrations of hybrid, as for RNase $A$ in (A). $\mathrm{RA}(15-24)(15-25 \mathrm{nM})$. RA(63-74) $(20-40 \mathrm{nM})$ and $\mathrm{RA}(112-116)$ $(20-40 \mathrm{nM})$, interpolated [or, in the case of RA(15-23), extrapolated] to the $50 \%$ inhibition level Values are the average of three independent measurements; for RA(15-24). of two independent measurements The estimated standard error from independent runs is given in parentheses. bata from St Clair et al. (1987)

This might explain the low catalytic activity of this hybrid with UpA as substrate. To explain the fact that activity with larger substrates is apparently retained (and perhaps somewhat 
increased), one must postulate that the lost interaction is compensated by interactions elsewhere between the hybrid and the larger substrate RNA.

What these additional interactions might be remains unclear. Nevertheless, the results reported here show the value of sequence comparisons in planning protein engineering experiments, and that much work remains before the differences in behavior in this class of proteins can be interpreted in terms of specific structural details.

\section{Acknowledgements}

We thank Professor H.Wyckoff for helpful comments conceming interactions in the RNase-phosphonate complex. We are indebted to the Swiss National Science Foundation, the ETH and Sandoz AG for partial support of this work.

\section{References}

Allemann,R.K. (1989) ETH Dissertation No. 8804

Barnard E A. (1969) Nature, 221, 340-344.

Blackbum,P and Moore,S. (1982) Enzumes, 15, 317-433.

Beintema,J.J., Broos.J., Meulenberg J and Schueller,C (1985) Eur. J. Biochem., 153. $305-312$

Benner.S.A (1987) Chumua, 41. 142-148

Benner,S.A. (1988) FEBS Lelt., 233, 225-228.

Benner,S.A. and Allemann,R.K. (1989) Trends Biochem Scl, 14, 396-397. Bradford,M. (1976) Anal. Biochem., 72, 248-254.

Burnette,W.N. (1981) Anal Brochem., 112, 195-203

Capasso,S , Giordano,F., Matta,C.A., Mazzarella,L. and Zagari,A. (1983) Biopolymers, 22, 327-332.

Creighton, T. (1979) J. Mol. Biol, 129, $411-431$.

D'Alessio,G. and Leone,E (1963) Brochem. J., 89, 7p

Fet.J.W., Strydorm,D J., Lobb.R.R., Alderman,E.M., Bethune.J.L., Ruordan.J.F and Vallee,B.L. (1985) Biochemistry, 24, 5480-5486

Folkman,J (1972) Ann Surg., 175, 409-416

Hanahan,D. (1983) J. Mol. Biol., 166, 557-580.

Harper,J.W. and Vallee,B.L. (1989) Biochemistry, 28, 1875- 1884

HIll.R.E. and Hastie, N.D. (1987) Nature, 326, 96-99.

Laskowskı,M., Jr, Kato,I , Kohr,W.J.. Park,S.J , Tashıro,M and Wahtley,H.E. (1987) Cold Spring Hartor Symp. Quant. Biol., 52, 545-553

Ipata,P L and Felicioli,R A (1968) FEBS Lett., 1, 29-31.

Kinsura,M (ed ) (1982) Molecular Elolution, Protein Polvmorphism, and the Neural Theon: Springer-Verlag, Berlın.

Kurachı.K., Davie,E.W. Strydom.D.J . Riordan,J F and Vallee.B L (1985) Biochemistry, 24, 5494-5499

McGeehan,G M and Benner,S A (1989) FEBS Lett, 247, 55-56.

MacPherson,A . Brayer.G . Cascio,D and Willams,R. (1986) Science, 232. $765-768$

Mazzarella,L., Mattia,C.A.. Capasso,S and dı Lorenzo,G (1987) Gazz Chim ltal., 117, 91-97

Matousek,J. (1973) Experientia, 29, 858-859.

Nambiar,K.P., Stackhouse,J., Stauffer.D.M., Kennedy.W.P , Eldredge.J K and Benner.S.A. (1984) Science, 223, 1299-1301

Nambiar.K.P.. Stackhouse,J., Prcsnell,R.S. and Benner,S.A. (1986) In Schenider, M (ed.), Enzwmes as Catalysts in Organic Synthesis. Riedel, Dordrecht, pp. 325-329

Nambiar,K.P., Stackhouse.J., Presnell,R S. and Benner,S.A (1987) Eur. J. Biochem , 163.67-71

Presnell,S R (1988) Thesis. Harvard University.

Richards,F M and Wyckoff.H W (1973) In Phillıps,D C and Richards,F M (eds), Atlas of Molecular Structures in Biology Clarendon Press, Oxford, pp. $000-000$

St Claır.D.K., Rybak.S.M., Rıordan.J.F. and Vallee,B.L. (1987) Proc. Natl Acad. Sci. USA, 84, 8330-8334

Seed,B. (1983) Nucleic Acuds Res., 11, 2427-2445

Shapiro,R., Riordan,J F and Vallee, B.L. (1986) Biochemistry, 25, 3527-3532

Stackhouse,J., Presnell.S.R., McGeehan,G.M., Nambiar,K.P and Benner,S.A (1990) FEBS Lett., 262, 104-106.

Strydom,D.J., Fett,J.W., Lobb,R R., Aldemran,E M , Bethune,J L., Rюrdan,J F and Vallee.B.L. (1985) Brochemustry, 24, 5486-5490

Sumuki,S., Parente,A., Fanna,B . Greco.L., La Montagna,R. and Leone.E. (1987) Bıol. Chem. Hoppe-Sevler, 268. 1305-1312.

Tanıguchi, T. and Libonatı.M (1974) Biochem. Biophys. Res. Commun. 58. $280-286$

Vescia,S. and Tramontano,D. (1981) Mol. Cell. Blochem., 36, 125-128.
Vescia,S.. Tramontano.D., Augusti-Tocco,G. and D'Alessio.G (1980) Cancer Res., 40, 3740-3744.

Wissler,J.H., Logemann,E., Meyer.H.E.. Kruetzfeldt.B . Hoeckel.M . Hellmeyer,L.M.G., Jr (1986) Prondes Biol. Fluids, 34, 525-536.

Wodak,S.Y., Liu,M.Y. and Wyckoff,H.W. (1977) J. Mol. Biol., 116, 855-875

Received on April 16, 1991; accepted on July 19, 1991 
